\title{
Effective Cloud Detection and Segmentation Using a Gradient-Based Algorithm for Satellite Imagery: Application to Improve PERSIANN-CCS $\mathscr{O}$
}

\author{
Negin Hayatbini, KuO-Lin Hsu, And Soroosh Sorooshian \\ Center for Hydrometeorology and Remote Sensing, Department of Civil and Environmental Engineering, \\ University of California, Irvine, Irvine, California \\ YUNJI ZHANG AND FUQING ZHANG \\ Department of Meteorology, The Pennsylvania State University, University Park, Pennsylvania
}

(Manuscript received 11 September 2018, in final form 4 March 2019)

\begin{abstract}
The effective identification of clouds and monitoring of their evolution are important toward more accurate quantitative precipitation estimation and forecast. In this study, a new gradient-based cloud-image segmentation algorithm is developed using image processing techniques. This method integrates morphological image gradient magnitudes to separate cloud systems and patches boundaries. A varying scale kernel is implemented to reduce the sensitivity of image segmentation to noise and to capture objects with various finenesses of the edges in remote sensing images. The proposed method is flexible and extendable from single to multispectral imagery. Case studies were carried out to validate the algorithm by applying the proposed segmentation algorithm to synthetic radiances for channels of the Geostationary Operational Environmental Satellite (GOES-16) simulated by a high-resolution weather prediction model. The proposed method compares favorably with the existing cloud-patch-based segmentation technique implemented in the Precipitation Estimation from Remotely Sensed Information Using Artificial Neural Networks-Cloud Classification System (PERSIANN-CCS) rainfall retrieval algorithm. Evaluation of event-based images indicates that the proposed algorithm has potentials comparing to the conventional segmentation technique used in PERSIANN-CCS to improve rain detection and estimation skills with an accuracy rate of up to $98 \%$ in identifying cloud regions.
\end{abstract}

\section{Introduction}

The purpose of this study is to improve the state-ofthe-art version of Precipitation Estimation from Remotely Sensed Information Using Artificial Neural NetworksCloud Classification System (PERSIANN-CCS) to support the National Aeronautics and Space Administration's (NASA) Integrated Multisatellite Retrievals for Global Precipitation Measurement (IMERG) algorithm of the Global Precipitation Measurement (GPM) mission for near-real-time monitoring of global precipitation at $0.1^{\circ} \times$ $0.1^{\circ}$ resolution over the chosen domain of $50^{\circ}-50^{\circ} \mathrm{S}$ with 30-min time intervals (Huffman et al. 2015). IMERG

\footnotetext{
Supplemental information related to this paper is available at the Journals Online website: https://doi.org/10.1175/JHM-D-180197.s1.
}

Corresponding author: Negin Hayatbini, nhayatbi@uci.edu consists of algorithms from the Climate Prediction Center (CPC) morphing technique (CMORPH) from NOAA (Joyce et al. 2004), the Tropical Rainfall Measuring Mission (TRMM) Multisatellite Precipitation Analysis (TMPA) from NASA (Huffman et al. 2007), and microwaverecalibrated PERSIANN-CCS (Hong et al. 2004).

The processing steps of PERSIANN-CCS algorithm include 1) cloud image segmentation, 2) image feature extraction and classification, and 3) rainfall mapping. Although PERSIANN-CCS has high spatial and temporal resolutions, it may sometimes overestimate or underestimate rainfall amount due to some of its limitations (Behrangi et al. 2009a). Despite recent developments to advance PERSIANN-CCS (Tao et al. 2016; Nasrollahi et al. 2013; Mahrooghy et al. 2012; Behrangi et al. 2009a), little attention is paid to improve the uncertainties within its cloud segmentation algorithm. Cloud image segmentation is the first and one of the most important steps in all precipitation retrieval algorithms. 
Rainfall estimation algorithms based on infrared (IR) cloud images can be categorized into three general groups depending on the method used for extracting information from the image: 1) pixel-based, 2) local-texturebased, and 3) patch-based algorithms (Hong et al. 2004). PERSIANN-CCS uses a cloud-patch-based technique and applies artificial neural networks to classify clouds (Nguyen et al. 2019). Precipitation is then estimated based on a relationship between precipitation rates and the cloud-top temperatures. PERSIANN-CCS segmentation combines thresholding and seeded region growing (SRG; Adams and Bischof 1994) algorithm to separate satellite images into distinctive cloud patches (Hong et al. 2004). The minimum brightness temperatures (Tbmin) of the cloud patches are determined to use as seeds. Then, the temperature threshold is raised to identify a new set of pixels neighboring the seeded points. This procedure continues until reaching the borders of other seeded regions or cloud-free regions. The temperature threshold is iteratively increased to a maximum of $253 \mathrm{~K}$. Afterward, a morphological operation is applied to merge tiny regions (Hong et al. 2004). Further details of the precipitation retrieval algorithm along with the segmentation process can be found in Hong et al. (2003, 2006).

Besides the patch-based algorithm used by PERSIANNCCS, several other algorithms have been developed to detect and segment clouds from satellite imageries, such as constant or changing threshold methods (Rossow and Garder 1993; Stowe et al. 1999; Kriebel et al. 2003; Bendix et al. 2004; EUMETSAT 2007; Sun et al. 2016), multidimensional histogram approaches (Kärner 2000), neural networks (Yhann and Simpson 1995; Tian et al. 1999; Jang et al. 2006), haze optimized transformation (HOT) algorithm (Zhang et al. 2002; Zhang and Guindon 2003), statistical and pattern recognition methods (Molnar and Coakley 1985; Kärner 2000; Murino et al. 2014), variational gradient-based fusion method ( $\mathrm{Li}$ et al. 2012), pixel-based seed identification, and object-based region growing - the watershed segmentation (Sedano et al. 2011; Beucher 1993; Vincent and Soille 1991).

Among these cloud detection techniques, the thresholdbased segmentation methods are the most broadly applied ones in satellite-based precipitation retrieval algorithms because they are simple, fast, and have agreeable accuracy (Hagolle et al. 2010; Jedlovec et al. 2008; Zhu et al. 2015). In threshold-based techniques, clouds are generally differentiated by a higher reflectance or lower temperature than the background or Earth surface. A major source of error comes from the complex land surface composition and the high variability of reflectivity in different cloud types. A threshold that is appropriate to a certain cloud type or a certain geographical region may not be applicable for another (Sun et al. 2016). Moreover, pixels defined by the threshold can only consider the radiometric and textural features of an individual pixel rather than contextual information provided by the image regions as objects (Blaschke et al. 2014). Hence, the potential implementation of an object-based approach designed to segment the clouds into meaningful objects independent of the predetermined threshold is superior to the aforementioned segmentation techniques in the context of patch-based precipitation retrieval algorithms.

In addition to the disadvantages of threshold-based algorithms, the segmentation process of IR-based rainfall estimation algorithms including PERSIANN-CCS have been using images from a single channel, with colder cloud-top brightness temperature indicates higher precipitation probabilities (Kidd et al. 2003; Huffman et al. 2007; Levizzani et al. 2001). However, different types of clouds may have similar cloud-top brightness temperatures in longwave IR channels (Sorooshian et al. 2000). Measurements from different channels can provide additional information about the structure and vertical profile of clouds that lead to more accurate rain estimates (Xu et al. 2005). A technique for cloud segmentation using multichannel information is expected to outperform those using single channels. For example, Behrangi et al. (2009b) used multispectral analysis to improve rain/no rain detection capabilities. They found that combining any two IR channels in the rain retrieval algorithm seems superior to the one using a single IR channel, and an improvement on the rain rate statistics can be gained.

This study is motivated by the recognition of the disadvantages of threshold-based segmentation techniques for patch-based precipitation retrieval algorithms. We introduce a mathematical morphology-based method that integrates the complementary multispectral information from the gradient magnitudes of satellite images and is a well fit in the context of PERSIANNCCS segmentation algorithm. This gradient-based multispectral segmentation (GMS) algorithm comprises several approaches that have been developed to extract various types of clouds including warm clouds. In this study, the algorithm is applied to model-simulated GOES-16 Advanced Baseline Imager (ABI) imagery. The simulated radiances for different channels of GOES-16 ABI along with the accompanying model simulated horizontal distribution of all clouds hydrometeors are used as the reference to validate the proposed algorithm in detecting and segmenting clouds.

Application of the proposed algorithm on real GOES-16 observation is also provided in the online supplemental material. Although the GMS algorithm is applied to geostationary satellite imageries in this study, it can be 
extended to other types of satellite datasets as well. This study will be the first step toward the ultimate goal which is precipitation estimation from remotely sensed information. In section 2, we explain the consisting steps of the developed GMS algorithm. Description of datasets and the case studies used in the study are described in section 3. Results and evaluation using both statistical scores and visual analyses are provided in section 4 . Last, the conclusions of this study are presented in section 5 .

\section{Methodology}

\section{GMS framework for cloud detection and} segmentation

The GMS algorithm is built on a hierarchical structure as the flow diagram shown in Fig. 1. This algorithm mainly carries out the following steps: multiscale gradient magnitude computation, markers generation, and watershed segmentation. They will be explained in the following subsections.

\section{1) Multiscale gradient magnitude COMPUTATION}

Gradient computation here means identifying the maximum change of each pixel's intensity in the neighborhood. The gradient highlights the sharp changes in intensity or the edges in an image. In a grayscale morphology, the gradient can be attained by subtracting the eroded image from the dilated image using a structuring element (Soille and Pesaresi 2002). Grayscale image pixels' value can be represented with the $x$ and $y$ coordinates as a three-dimensional set (Parvati et al. 2008). With this concept, grayscale dilation can be defined as follows.

Let $f(s, t)$ represent an image and $B(x, y)$ be the structuring element. The structuring element (kernel) is a group of pixels of different sizes and shapes. In this study, a flat kernel, which means a squared window of pixels with equal weights, is considered for simplicity. Grayscale dilation of $f$ by $B$ is defined as below:

$$
\begin{aligned}
(f \oplus B)_{(s, t)}= & \max \{f(s-x, t-y) \\
& \left.+B(x, y) \mid(s-x),(t-y) \in D_{f} ;(x, y) \in D_{B}\right\} .
\end{aligned}
$$

Grayscale erosion of $f$ by $B$ is defined as below:

$$
\begin{aligned}
(f \ominus B)_{(s, t)}= & \min \{f(s+x, t+y) \\
& \left.-B(x, y) \mid(s+x),(t+y) \in D_{f} ;(x, y) \in D_{B}\right\},
\end{aligned}
$$

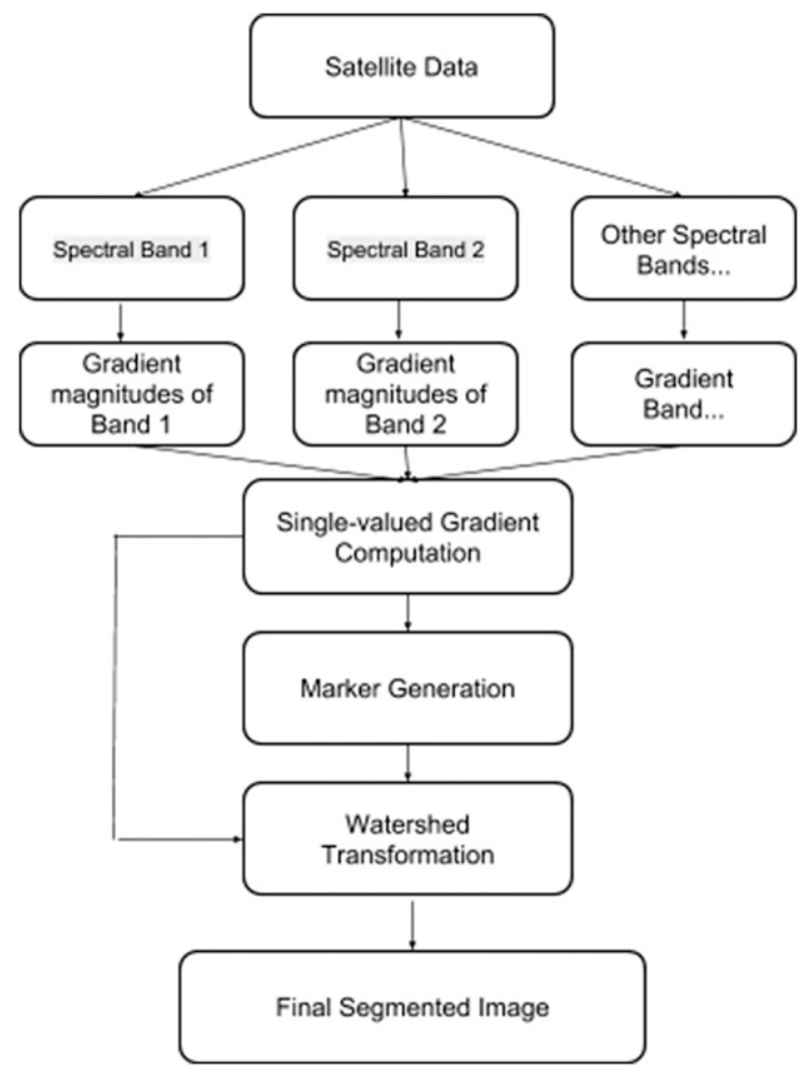

FIG. 1. Flow diagram of the proposed multispectral gradient-based segmentation algorithm.

where $D_{f}$ and $D_{B}$ are the domains of $f$ and $B$, respectively. The conditions that $(s+x)$ and $(t+y)$ have to be in the domain of $f$ and $(x, y)$ have to be in the domain of $B$ is equivalent to the condition in the binary description of dilation and erosion. Two sets have to at least share one pixel in common in dilation, however, the structuring element has to be completely contained by the set being eroded in erosion (Pahsa 2006). For further details on the erosion and dilation operations please refer to Gonzalez and Woods (1992).

The gradient image is calculated using Eq. (3) below from the original image, and it corresponds to the sharpness of the intensity change for each pixel (Parvati et al. 2008):

$$
\operatorname{MG}(f)=(f \oplus B)-(f \ominus B) .
$$

A multiscale gradient algorithm capable of utilizing a varying scale-structuring element in mathematical morphology is implemented to reduce the sensitivity to noise and to extract various finenesses of the edges of the objects in remote sensing images (Wang 1997):

$$
\operatorname{MG}(f)=\frac{1}{n} \sum_{i=1}^{n}\left\{\left[\left(f \oplus B_{i}\right)-\left(f \ominus B_{i}\right)\right] \ominus B_{i-1}\right\},
$$


where $B_{i}$ denotes the group of square structuring elements with the size of $(2 i+1) \times(2 i+1)$ pixels and $n$ is the scale which in this study is set to value of 5 . Component-wise and vector-based strategies can be used to extend mathematical morphology from a singlechannel grayscale image to a multichannel image (Comer and Delp 1999). The component-wise strategy processes each channel of the multispectral image separately, while the vector-based strategy uses a vector approach to process the multispectral channels all at once (Soille 2003). In this study, the component-wise approach is used for multispectral gradient image computation, since it is easy to implement and the results are satisfying. The morphological gradient (MG) is calculated separately for each band $f$ from Eq. (5), and the resulting gradient image values are combined via equal weighted summation to generate a single gradient image to represent different channels. This way the gradient values can be obtained by summing up the complementary measurements from multiple channels of satellite imagery:

$$
\operatorname{MG}(f)=\sum_{i=1}^{n} \operatorname{MG}\left(f_{i}\right)
$$

\section{2) MARKER GENERATION AND LOCAL MINIMA ELIMINATION}

Markers are the selected regional minima of the input image, which are being used before watershed transform. The reason to employ so-called markers is to reduce redundant catchment basins due to the high sensitivity of the watershed transformation algorithm to noise and irrelevant local minima. The generation of pertinent markers is important to the successful application of watershed segmentation (Soille and Pesaresi 2002).

The markers are either single points or regions that are placed inside objects of interest (Parvati et al. 2008). In this study, we generated markers through automatic thresholding of gradient magnitudes. Clusters of image pixels are classified as seed or nonseed pixels using the Otsu thresholding method (Otsu 1979), which automatically selects an optimal threshold based on maximizing the separability of the group-wise pixel values in gray levels, to generate the marker image. It selects a satisfactory threshold level to extract objects from their background based on a gray-level histogram. The reason to implement this method is based on the histogram plot of the gradient magnitudes shown in Fig. 2 that gradient magnitudes of most pixels are confined to the lower value range, while the sharp edge pixels with large gradient magnitudes are greater

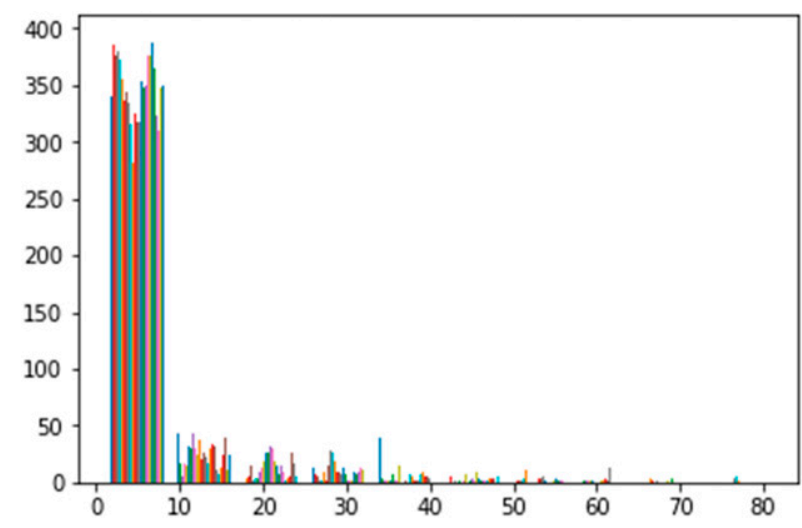

FIG. 2. Histogram plot of the gradient magnitude image. The horizontal axis shows the range of gradient magnitude values, and the vertical axis is the number of pixels with each gradient magnitude value.

and separable from those within the background. For further explanation of this thresholding method and examples, one can refer to Otsu (1979) and Zhang et al. (2014).

\section{3) WATERSHED SEGMENTATION ON THE GRADIENT IMAGE}

The watershed transformation (Vincent and Soille 1991) is a powerful segmentation algorithm from mathematical morphology and has been used in many segmentation problems (Hsu et al. 2010; Zahraei et al. 2013; Lakshmanan et al. 2009). This approach is usually applied to satellite images to extract regions (i.e., objects) that are identified as clouds. The basic idea of the watershed algorithm is to consider the single channel image as a three-dimensional topography map where the lower values are considered as valleys (local minima) and the higher values are assumed to be hills. Each local minimum is then flooded to neighboring pixels until meeting an adjacent catchment. A ridgeline is then delineated along any two regions' borders, hence the catchment basins are delimited by watershed lines (Fig. 3). Further information about the watershed segmentation algorithm can be found in Vincent and Soille (1991).

The morphology-based watershed transformation used in this study is applied to the gradient magnitude of satellite images. This is different from the traditional segmentation used in PERSIANN-CCS algorithm that the watershed transformation is directly applied on temperature values lower than a predefined threshold. Applying transformation on gradient images can capture warm clouds without dependency on predefined temperature thresholds as a controlling factor. Figure $4 \mathrm{a}$ demonstrates how local minima associated with warmer 


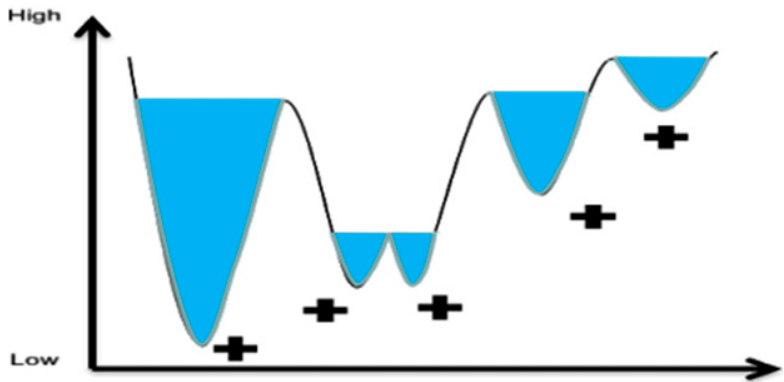

FIG. 3. Watershed transformation process diagram. Each of the positive signs represents one watershed domain.

cloud regions will be disregarded by a predefined threshold applied to the values before implementing the watershed algorithm. Increasing the temperature threshold in order to capture the clouds with the higher temperature values (Fig. 4b) results in merging the local minima which are representative of distinct clouds and causes misleading outcomes. Optimal results are achieved when the watershed algorithm is applied to the gradient magnitude images that delineate the boundaries of all types of clouds, regardless of their height or temperature. In Fig. 4c, high gradient magnitude values are representative of pixels with sharp intensity transitions or cloud boundaries. Hence, the catchment basins are described as regions between any two local maximum of the gradient magnitudes.

\section{Description of the datasets}

\section{a. GOES-16 $A B I$}

The primary datasets collected and processed in this research include different channels of geostationary weather satellite bands of GOES-16. The ABI (Schmit et al. 2005) on board GOES-16 can provide more accurate, detailed, and timely detection of high-impact environmental phenomena by more spectral channels ( 2 visible, 4 near-infrared, and 10 infrared channels), and higher spatial $(2 \mathrm{~km} \times 2 \mathrm{~km}$ at nadir for infrared channels) and temporal (every $5 \mathrm{~min}$ for the contiguous United States) resolutions over its predecessors. The development of the $\mathrm{ABI}$ is being done as a collaborative effort between NASA and NOAA. For readers interested in further details, Schmit et al. (2005) is considered as the reference.

\section{b. PSU WRF-EnKF dataset}

We used two simulated cases to examine the performance of the proposed algorithm. Both two simulations are generated using the Weather Research and Forecasting (WRF) Model with its Advanced Research version of WRF (ARW) dynamical core (Skamarock et al. 2008), with initial conditions generated by the WRF-based ensemble Kalman filter (EnKF) data assimilation system developed at The Pennsylvania State University (Zhang et al. 2009, 2011).

The first case study is a simulation of Hurricane Harvey (2017), which brought record-breaking catastrophic rainfall in southern Texas. Harvey is the second costliest hurricane in history, just below Hurricane Katrina (2005), and it is also the first storm that was fully captured by $G O E S-16$. The simulation utilized version 3.6.1 of the WRF Model with a 3-km horizontal resolution. After assimilating brightness temperature observations from ABI every $1 \mathrm{~h}$ for several cycles, the deterministic forecast is initialized from the EnKF analysis at 0600 UTC 23 August 2017. For the purpose of this study, we only used simulated brightness temperature of the model outputs of a 1-day period from 0000 UTC 26 August to 0000 UTC 27 August, right after Harvey made its landfall.

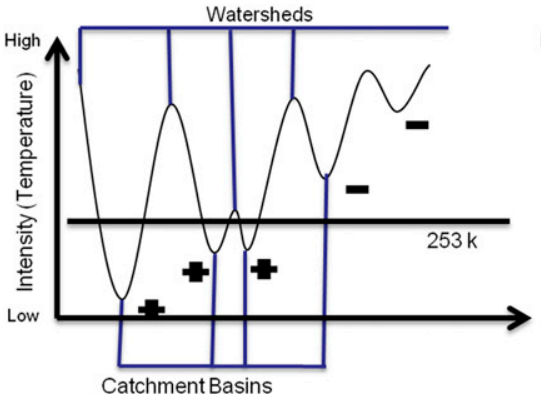

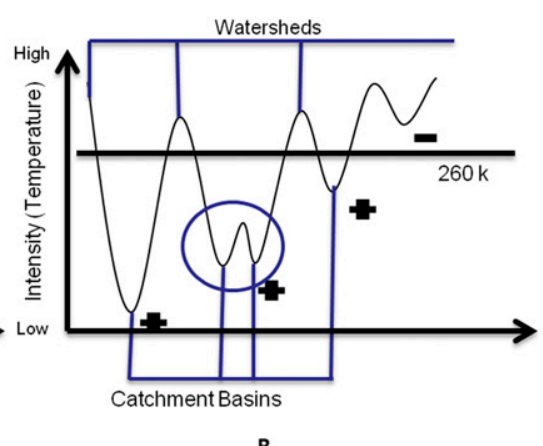

B

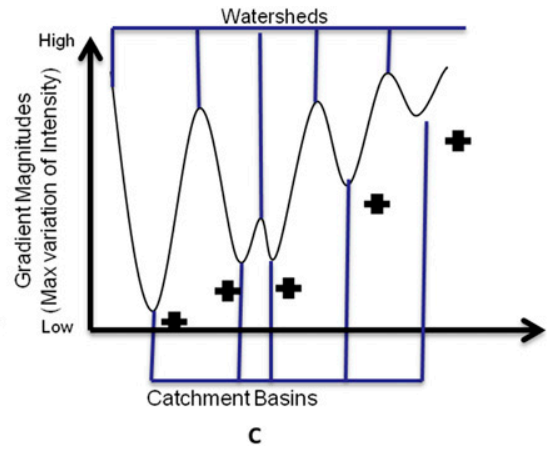

FIG. 4. Schematic representation of the watershed segmentation technique applied (a),(b) on the image values after applying predefined thresholds and (c) on the image gradient magnitudes. The positive and negative signs each represent the separate cloud regions that are included and excluded, respectively, in the segmentation process. 


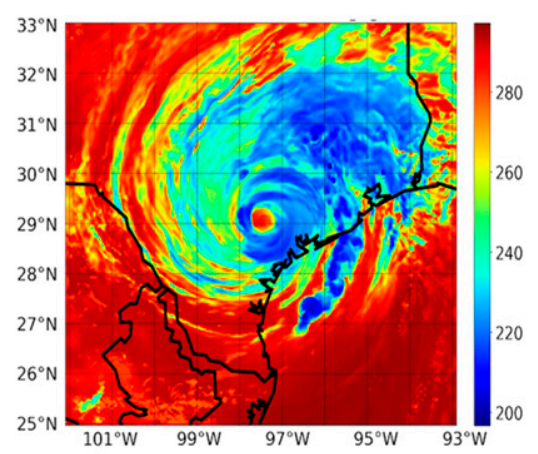

A

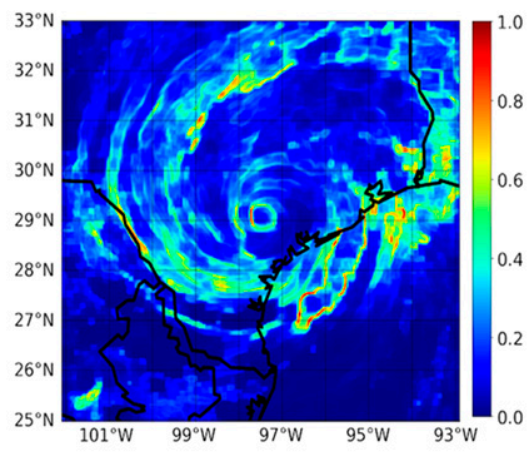

B

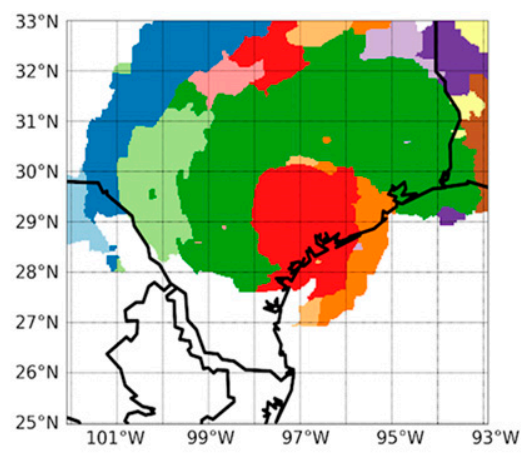

C

FIG. 5. Visualization of the gradient-based segmentation result for the simulated Hurricane Harvey event at 0300 UTC 26 Aug 2017 : (a) simulated IR longwave window band from GOES-16 ABI (the scale bar is temperature in K), (b) normalized gradient magnitudes imagery for the corresponding simulated IR channel (scale bar is normalized gradient magnitude values), (c) resulting cloud segments (each random color represents a distinct segment). The vertical and horizontal axes represent the latitude and longitude of the region, respectively.

Further details of the simulation of Hurricane Harvey, including verifications of its track, intensity, and cloud forecasts with observations can be found in Zhang et al. (2019).

The second case is a simulation of tornadic supercell thunderstorms across Wyoming, Nebraska, and Colorado on 12 June 2017, which is one of the first severe thunderstorm event captured by GOES-16. The simulation utilized version 3.8.1 of the WRF Model with a $1-\mathrm{km}$ horizontal resolution. Brightness temperature observations from $\mathrm{ABI}$ are assimilated every $5 \mathrm{~min}$, and the deterministic forecast is initialized from EnKF analysis at 2000 UTC 12 June 2017, when the thunderstorms were just initiated. The simulations were carried out until 0000 UTC 13 June 2017, with outputs every $5 \mathrm{~min}$. Further details of the simulation of this severe thunderstorm event and the verifications of the thunderstorm predictions with the observations can be found in Zhang et al. (2018).

These two cases differ significantly in the strength and size of clouds. The tornadic supercell thunderstorm case is one of the smallest organized cloud systems and occur mostly over the midlatitude continents, while hurricanes have the largest and most expansive cloud systems originating from the tropical oceans. We can examine the strength and flexibility of the proposed algorithms using these two distinctive situations to see if it can detect diverse types of clouds effectively by utilizing fixed parameter values.

\section{Results and discussion}

Experiments are carried out to validate the GMS algorithm by applying it to the model-simulated GOES-16
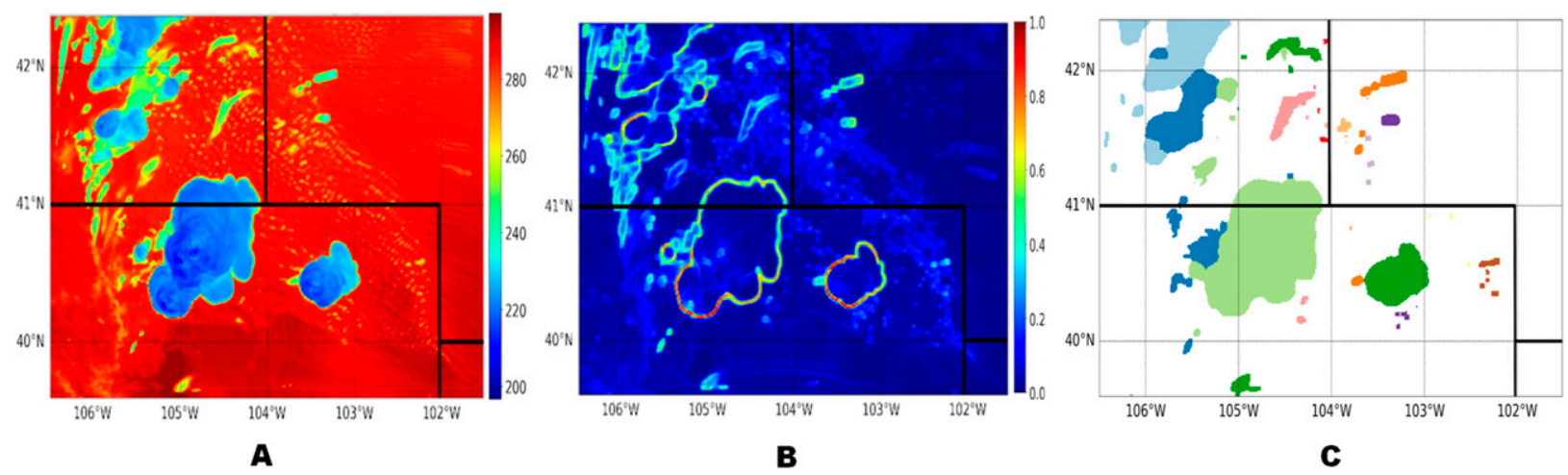

FIG. 6. Visualization of the gradient-based segmentation result for the simulated Wyoming tornado event at 2120 UTC 12 Jun 2017 : (a) simulated IR longwave window band from GOES-16 ABI (the scale bar is temperature in K), (b) normalized gradient magnitudes imagery for the corresponding simulated IR channel (scale bar is normalized gradient magnitude values), (c) resulting cloud segments from GMS (each random color represents a distinct segment). 


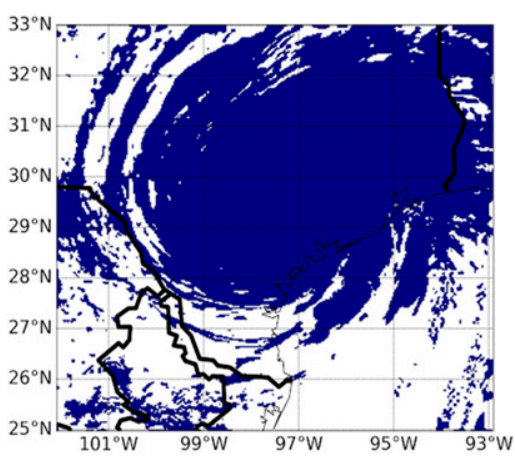

A

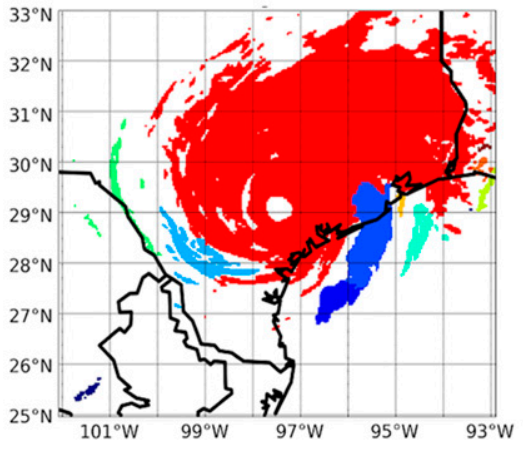

B

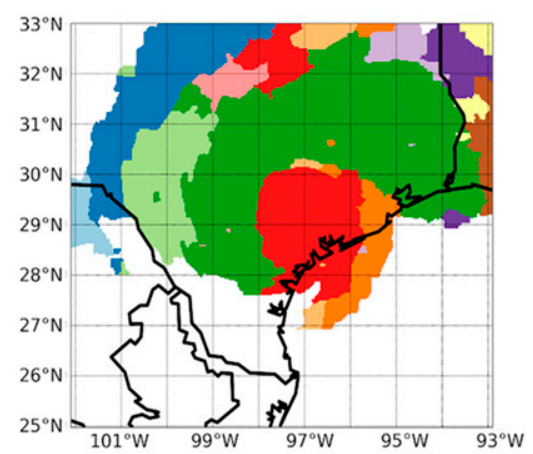

C

FIG. 7. Visual comparison of the two segmentation outputs based on the truth mask as a reference for the simulated Hurricane Harvey event at 0300 UTC 26 Aug 2017. (a) Truth cloud mask used as a reference. The dark blue region implies the cloud existence. (b) PERSIANN-CCS segmentation result from single-IR channel. (c) Gradient-based segmentation algorithm output based on only the IR channel. In (b) and (c), each random color identifies a distinct cloud patch.

ABI imageries, and compare with the accompanying synthetic cloud mask from the horizontal distribution of all cloud hydrometeors known as the "ground truth."

Visual comparisons and statistical evaluations are performed for both cases to obtain the accuracy of the proposed segmentation algorithm in comparison to the single-channel, threshold-based segmentation approach that is currently in use for PERSIANN-CCS. Although the GMS algorithm is capable of integrating information from different spectral bands, the results shown in this section are obtained from single-band IR cloudtop brightness temperature in order to be consistent with the PERSIANN-CCS single-band segmentation algorithm.

\section{a. Visual comparison}

The final gradient-based segmentation results from simulated IR input along with gradient magnitude imageries of Hurricane Harvey and the Wyoming thunderstorm event are shown in Figs. 5 and 6, respectively. The gradient magnitudes are calculated from the IR images and the watershed segmentation is then applied to the gradient magnitude imageries based on the generated markers to achieve the final cloud patch segmentation.

Figures 7 and 8 show that in both cases the newly developed algorithm can capture more types of clouds, especially the warmer ones compared with the PERSIANNCCS in reference to the truth cloud mask from the model simulations. This indicates that the gradientbased segmentation algorithm is capable of overcoming the drawback associated with threshold-based segmentation approaches implemented in patch-based precipitation retrieval algorithms.

As mentioned in the methodology section, the gradient-based segmentation algorithm is capable of taking into account the complementary measurements

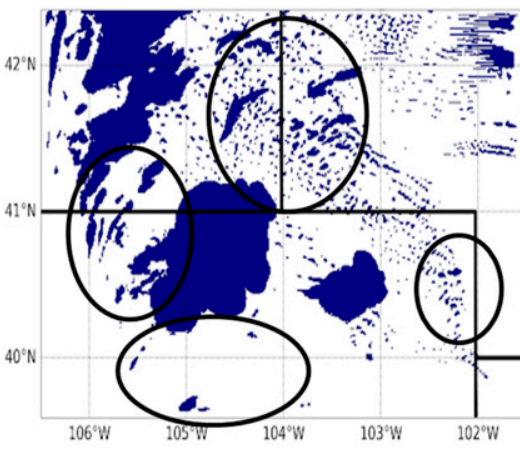

A

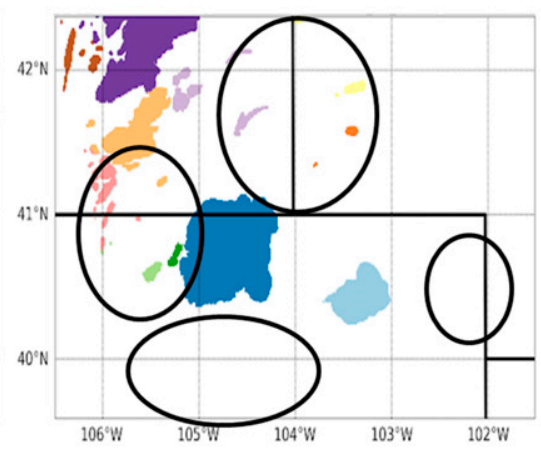

B

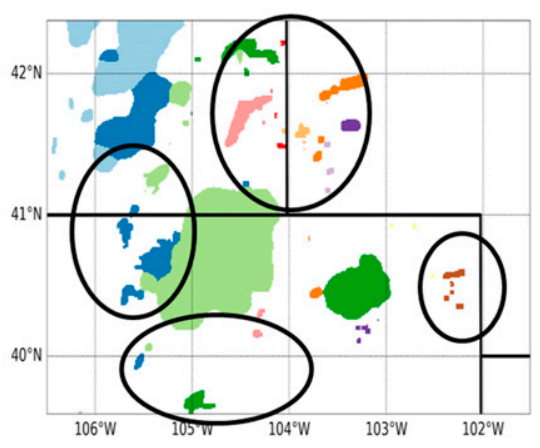

C

FIG. 8. Visual comparison of the two segmentation outputs based on the truth mask as a reference for the simulated Wyoming tornado event at 2120 UTC 12 Jun 2017. (a) Truth cloud mask used as a reference. The dark blue region implies the cloud existence. (b) PERSIANN-CCS segmentation result from single-IR channel. (c) Gradient-based segmentation algorithm output based on only the IR channel. In (b) and (c), each random color identifies a distinct cloud patch. 

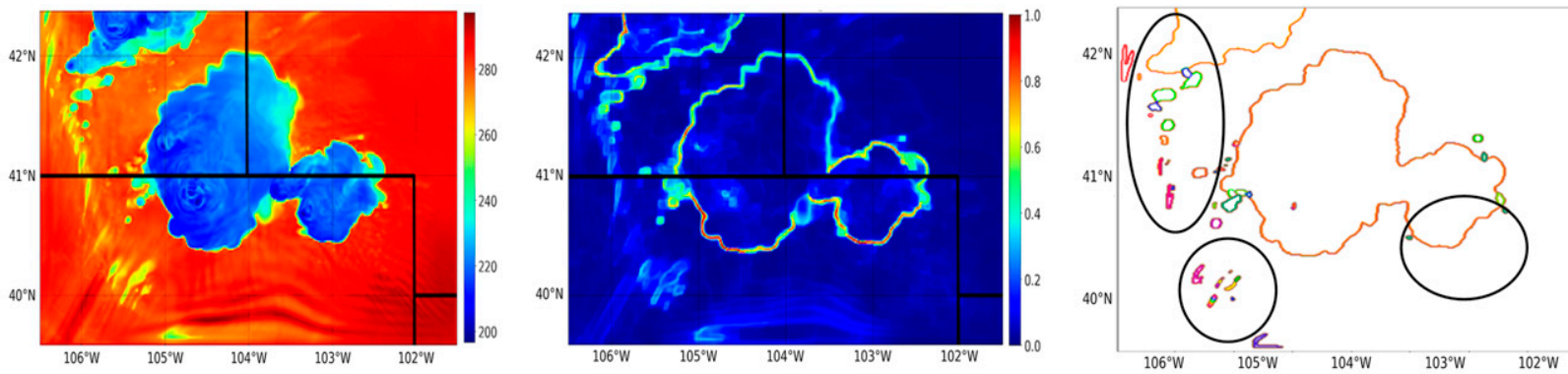

A
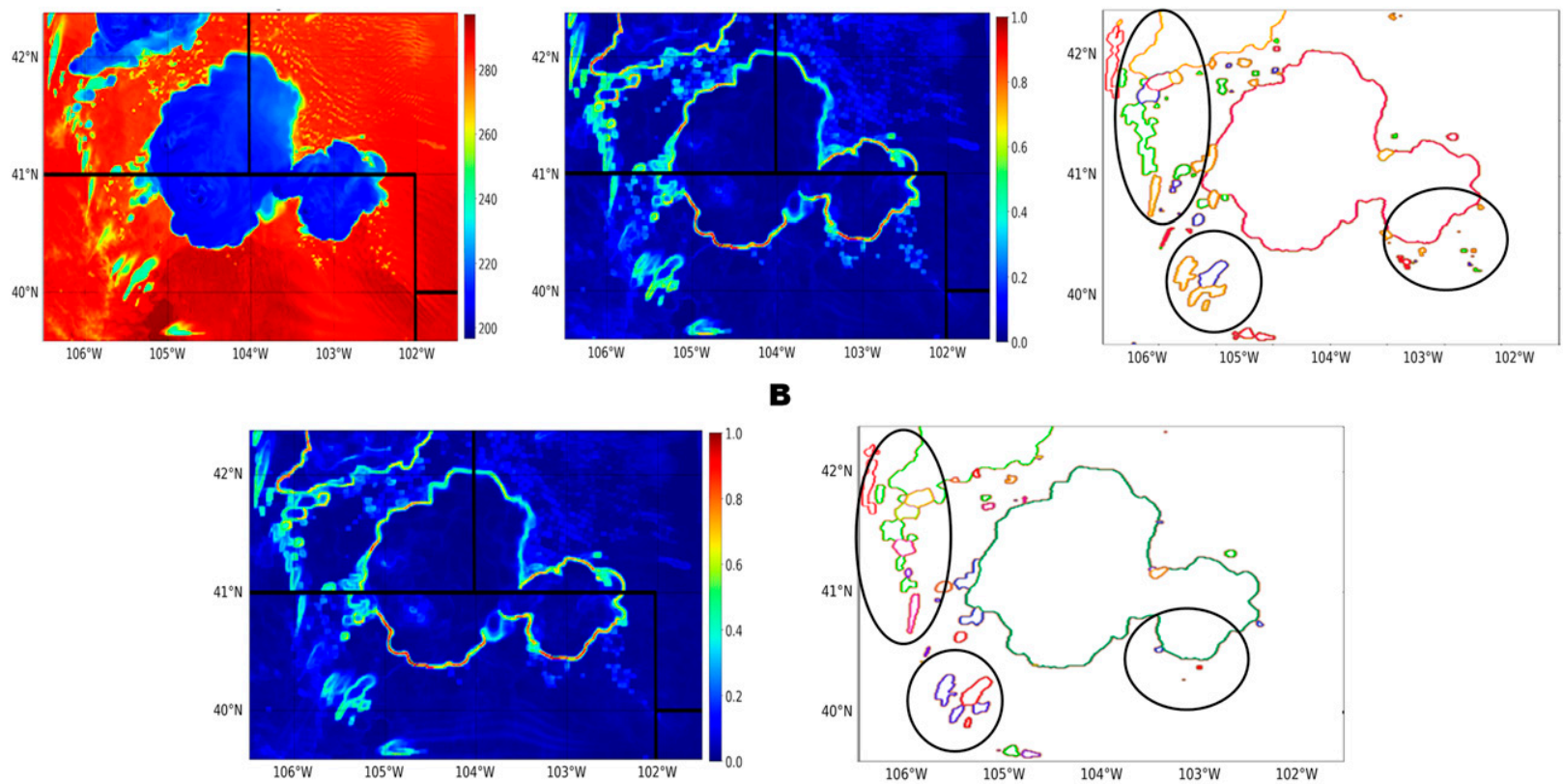

C

FIG. 9. Visualizing the effect of integrating complementary information from lower-level water vapor for the Wyoming tornado case at 2105 UTC 12 Jun 2017. (a) Final cloud segments from the gradient magnitudes of lower water vapor band. (b) Final cloud segments from the gradient magnitudes of single-IR longwave window band. (c) Final cloud segments from the combined gradient magnitude image of both spectral bands (IR longwave window and water vapor band).

from multiple channels. To visually assess the effect of integrating information from other spectral bands, channel 8 (lower-tropospheric water vapor channel) of the GOES-16 ABI is also processed and gradient magnitudes are calculated separately for this band. The gradient values from each spectral band are then summed up to generate a single-valued multispectral gradient magnitude image. The watershed segmentation is then applied to the combined gradient magnitude imagery.

The segmentation results from each scenario (IR only and IR + water vapor) are shown in Fig. 9 implying that integration of measurements from other spectral bands will provide useful information for distinct delineation of the clouds and helps to discard cloud patches that are mistakenly detected due to the background noise in the utilization of single channel data. Adding additional channels provides useful information for better defining the cloud segments and leads to a more accurate classification as the next step toward more robust intensity estimation and areal delineation of rainfall.

\section{b. Statistical evaluation}

A reference cloud mask is needed in order to perform an accuracy assessment and to compare the outcomes of the proposed segmentation algorithms. The modelsimulated mixing ratios combining all hydrometeors, including cloud water, cloud ice, rainwater, snow, and graupel, are used as "truth" observation mask to determine whether a grid point is covered by cloud or not. These hydrometeor mixing ratios are prognostic model variables simulated by the microphysics scheme and evolve in correspondence with the dynamical and 
TABLE 1. The four possible diagnosis results of testing.

\begin{tabular}{llll}
\hline & \multicolumn{1}{c}{ Detected } & \multicolumn{1}{c}{ Not detected } & Probability \\
\hline Existing & True positive (TP) & False negative (FN) & TP + FN $=100 \%$ \\
Nonexisting & The existing defect is detected (hit) & The existing defect is not detected (miss) & FP + TN $=100 \%$ \\
& $\begin{array}{l}\text { False positive (FP) } \\
\text { A defect is detected even though it } \\
\text { does not exist (false alarm) }\end{array}$ & $\begin{array}{l}\text { True negative (TN) } \\
\text { No defect is detected, where no defect } \\
\text { exists (correct rejection) }\end{array}$ & FN \\
Total & FP + TP & FN & Total $=$ TP + FN + TN + FP \\
\hline
\end{tabular}

thermodynamical processes within the WRF Model. After summing them all together and taking the vertical maximum value within each column, a threshold of $10 \times$ $10^{-6} \mathrm{~kg} \mathrm{~kg}^{-1}$ is applied to the horizontal hydrometeor mixing ratio map. This value is a widely used threshold for cloud-top and cloud-base identification from model simulations beginning from Otkin and Greenwald (2008). The grid point is cloudy if the hydrometeor mixing ratio at this location is greater than the threshold and is clear sky if it is lower than the threshold. The model-derived horizontal distribution of clouds is used as the truth to verify and compare the two different cloud identification algorithms. The situations of whether the segmentation algorithm detects the clouds successfully or not are shown in Table 1 with the verification indices used along with their application listed in Table 2.

Constant improvements in segmentation skill using the GMS algorithm are evident for both events with their cloud systems evolving considerably in structure and morphology (Figs. 10, 11). The improvement is pronounced when only IR data are used to keep the consistency between the proposed segmentation algorithm and the one used in PERSIANN-CCS. The only metric that is not showing the performance enhancement is the false alarm ratio (FAR; with the best score of zero), with a nonzero but insignificant average value of 0.03 (Figs. 10b, 11b). This higher value of FAR is in compensation for the higher POD that we obtained in comparison to the PERSIANN-CCS segmentation algorithm. The conventional segmentation algorithm misses clouds with higher temperatures than the manually set temperature threshold and only captures the colder clouds. Therefore, low or zero FAR is expected. The gradient-based segmentation algorithm, on the other hand, can cover both warm and cold clouds with potentially higher FAR.

\section{Summary and conclusions}

A gradient-based multispectral segmentation algorithm for cloud detection and segmentation using satellite imageries is developed and presented. The goal is to provide a more effective and flexible method to overcome the shortcomings associated with the traditional patch-based cloud segmentation approaches toward more reliable precipitation retrievals. This algorithm is based on mathematical morphology, and image processing techniques developed to extract information from single or multiple channels of satellite imagery. Due to the unique characteristics of each spectral band, accumulation of additional sources of information from multichannel satellite imagery became viable by using the gradient magnitudes instead of directly utilizing each channel's values. This gradient-based cloud image segmentation method integrates morphological image gradient magnitudes to separable cloud systems and patches boundaries

TABLE 2. Verification metrics.

\begin{tabular}{|c|c|c|c|}
\hline Verification metrics & Formulation & Range & Application \\
\hline Undetected error rate & $\begin{array}{l}\mathrm{Ur}=\text { Misses/number of } \\
\text { observed events }\end{array}$ & $(0 \leq \mathrm{Ur} \leq 1) ;$ perfect score: 0 & $\begin{array}{l}\text { The rate of error in detection } \\
\text { of hit events }\end{array}$ \\
\hline Probability of detection & $\begin{array}{l}\text { POD }=\text { Hits/number of } \\
\text { observed events }\end{array}$ & $\begin{array}{l}(0 \leq \mathrm{POD} \leq 1) ; \text { perfect } \\
\text { score: } 1\end{array}$ & $\begin{array}{l}\text { The likelihood of correct } \\
\text { detection }\end{array}$ \\
\hline False alarm ratio & $\begin{array}{l}\mathrm{Fr}=\text { False alarm/number of not } \\
\text { observed events }\end{array}$ & $(0 \leq \mathrm{Fr} \leq 1) ;$ perfect score: 0 & $\begin{array}{l}\text { The number of false alarms } \\
\text { per total number of alarms }\end{array}$ \\
\hline Bias score & $\begin{array}{l}\text { Bias }=(\text { Hits }+ \text { false alarms }) / \text { number } \\
\quad \text { of observed events }\end{array}$ & $(0 \leq$ Bias $) ;$ perfect score: 1 & $\begin{array}{l}\text { How similar were the } \\
\text { frequencies of existing } \\
\text { and detected events? }\end{array}$ \\
\hline $\begin{array}{l}\text { Equitable threat } \\
\text { score (ETS) }\end{array}$ & $\begin{array}{l}\mathrm{ETS}=\text { Hits }- \text { hitsrandom } /(\text { hits }+ \\
\quad \text { misses }+ \text { false alarms }- \text { hitsrandom })\end{array}$ & $\begin{array}{l}(-1 / 3<\text { ETS }<1) ; \text { perfect } \\
\text { score: } 1\end{array}$ & $\begin{array}{l}\text { How well did the existing } \\
\text { events correspond to the } \\
\text { detected events? }\end{array}$ \\
\hline
\end{tabular}




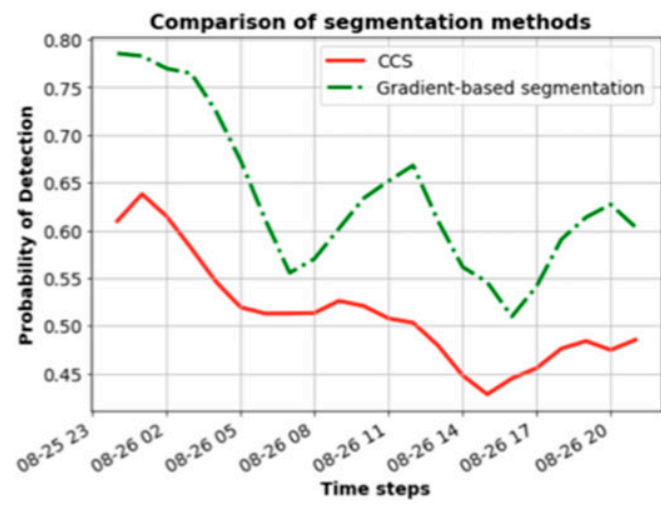

A

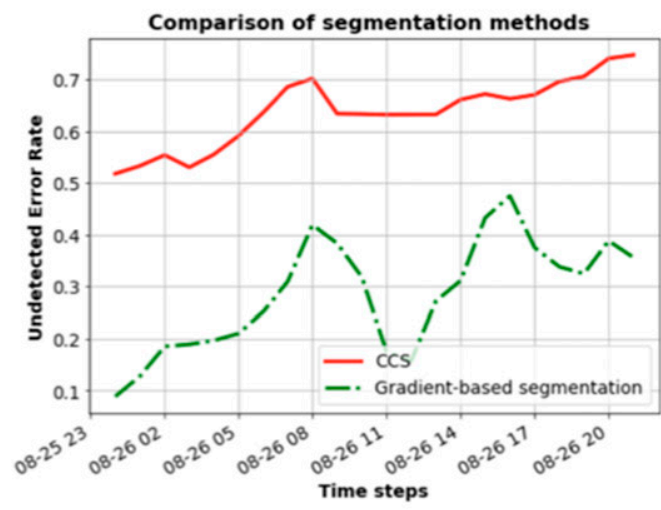

C

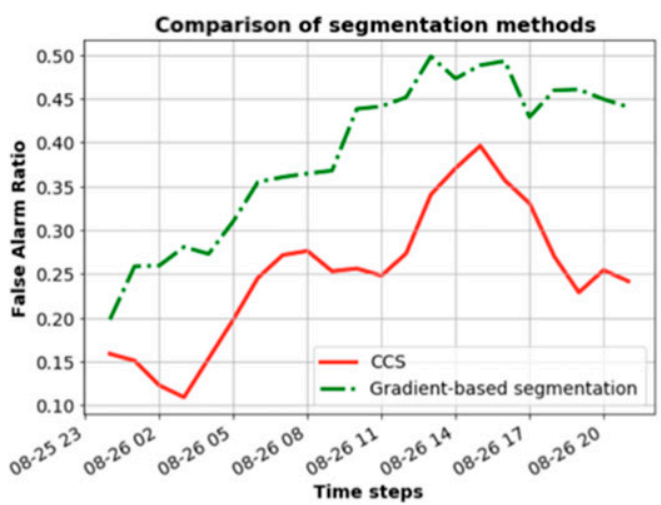

B

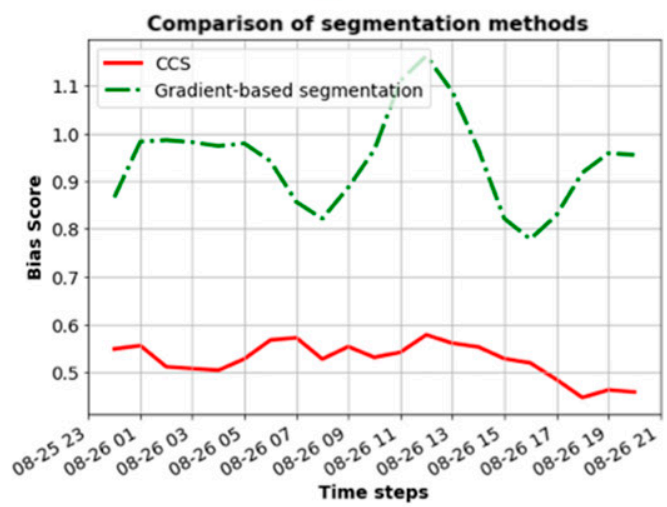

D

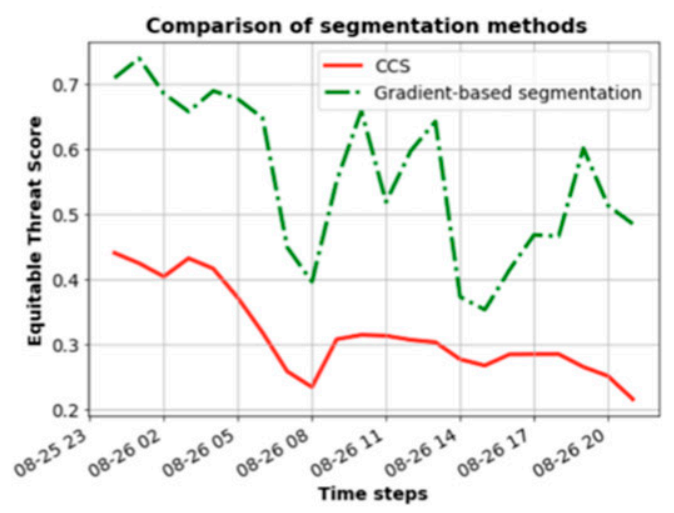

$\mathrm{E}$

FIG. 10. Statistical comparison of two different segmentation algorithms for the Hurricane Harvey case: (a) POD, (b) FAR, (c) undetected error rate, (d) bias score, and (e) equitable threat score.

using a convolution operation. As a result, a wider range of cloud types regardless of their temperature and height can be detected and segmented. The proposed algorithm, as well as the conventional threshold-based segmentation approach used in the PERSIANN-CCS algorithm, is applied on the simulated GOES-16 ABI imageries from high-resolution numerical weather simulations accompanied with their modeled horizontal distribution of hydrometeors as the reference to examine their performance. Results from visual and statistical comparison indicate a constant improved performance of the gradient-based segmentation technique over the traditional approaches specifically in terms of extracting warm cloud regions. More accurate extraction of cloud patches provides the opportunity for a more effective cloud tracking toward dynamic analysis of precipitation estimation. This algorithm is the first step toward reducing the uncertainty 


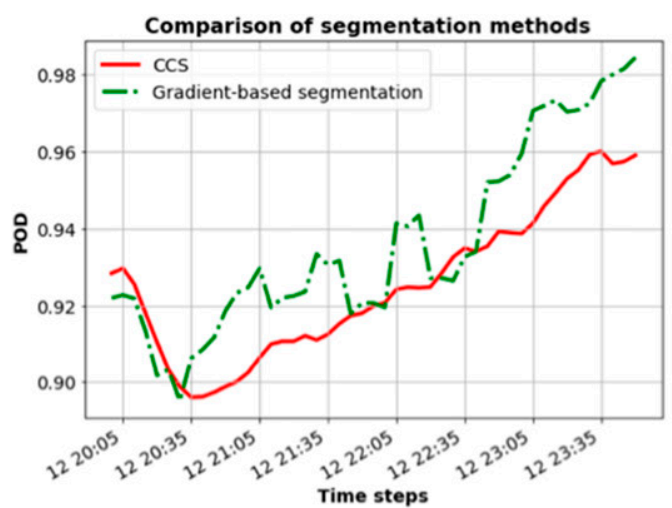

A

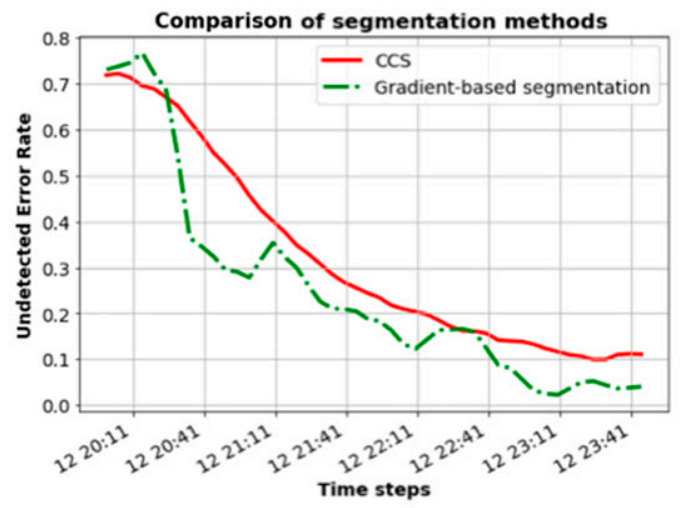

C

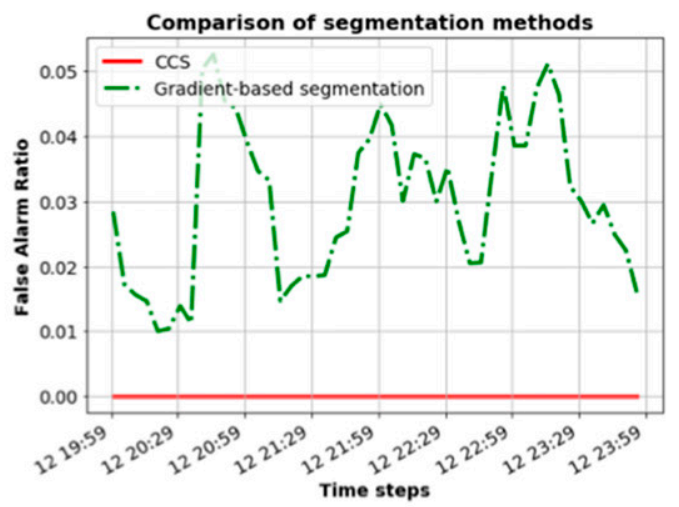

B

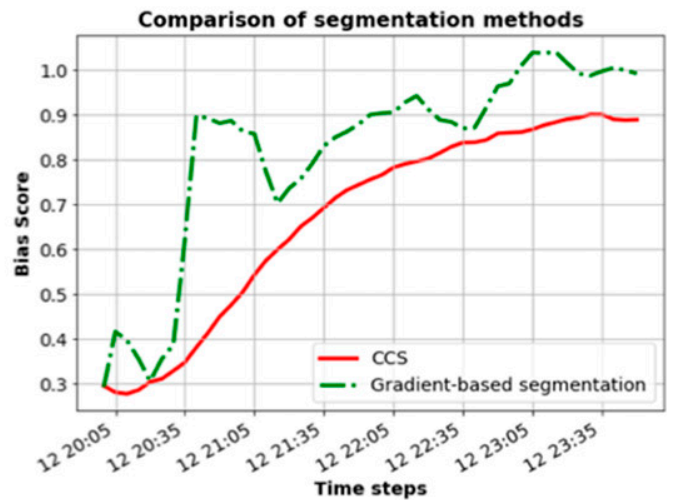

D

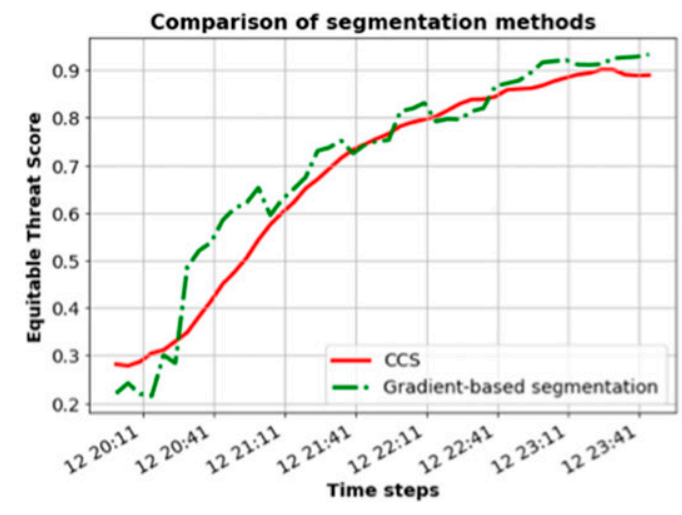

E

FIG. 11. Statistical comparison of two different segmentation algorithms for the Wyoming Tornado case: (a) POD, (b) FAR, (c) undetected error rate, (d) bias score, and (e) equitable threat score.

associated with precipitation retrieval from remotely sensed information.

Acknowledgments. The financial support for this research is from U.S. Department of Energy (DOE Prime Award DE-IA0000018), California Energy Commission (CEC Award 300-15-005), MASEEH fellowship, NSF CyberSEES Project (Award CCF-1331915),
NOAA/NESDIS/NCDC (Prime Award NA09NES4400006 and subaward 2009-1380-01), and a NASA Earth and Space Science Fellowship (Grant NNX15AN86H). The participation of the Pennsylvania State University coauthors is supported by NASA Grants NNX16AD84G and NNX12AJ79G. The Harvey WRF forecast used here was conducted and provided by Masashi Minamide. Data assimilation and numerical simulations were 
performed on the Stampede supercomputer of the Texas Advanced Computing Center (TACC). Finally, authors would like to sincerely thank the valuable comments and suggestion of the editors and the anonymous reviewers.

\section{REFERENCES}

Adams, R., and L. Bischof, 1994: Seeded region growing. IEEE Trans. Pattern Anal. Mach. Intell., 16, 641-647, https://doi.org/ 10.1109/34.295913.

Behrangi, A., K.-l. Hsu, B. Imam, S. Sorooshian, G. J. Huffman, and R. J. Kuligowski, 2009a: PERSIANN-MSA: A precipitation estimation method from satellite-based multispectral analysis. J. Hydrometeor., 10, 1414-1429, https://doi.org/ 10.1175/2009JHM1139.1

,,,$----\frac{-}{-}$ and R. J. Kuligowski, 2009b: Evaluating the utility of multispectral information in delineating the areal extent of precipitation. J. Hydrometeor., 10, 684-700, https:// doi.org/10.1175/2009JHM1077.1.

Bendix, J., R. Rollenbeck, and W. Palacios, 2004: Cloud detection in the tropics-A suitable tool for climate-ecological studies in the high mountains of Ecuador. Int. J. Remote Sens., 25, 4521-4540, https://doi.org/10.1080/01431160410001709967.

Beucher, S., 1993: Segmentation tools in mathematical morphology. Handbook of Pattern Recognition and Computer Vision, World Scientific, 443-456.

Blaschke, T., and Coauthors, 2014: Geographic object-based image analysis-Towards a new paradigm. ISPRS J. Photogramm. Remote Sens., 87, 180-191, https://doi.org/10.1016/ j.isprsjprs.2013.09.014.

Comer, M. L., and E. J. Delp, 1999: Morphological operations for color image processing. J. Electron. Imaging, 8, 279-290, https://doi.org/10.1117/1.482677.

EUMETSAT, 2007: Cloud detection for MSG-Algorithm theoretical basis document. Doc. EUM/MET/REP/07/0132, 26 pp.

Gonzalez, R. C., and R. E. Woods, 1992: Digital Image Processing. Addison-Wesley, $716 \mathrm{pp}$.

Hagolle, O., M. Huc, D. V. Pascual, and G. Dedieu, 2010: A multi-temporal method for cloud detection, applied to FORMOSAT-2, VEN $\mu$ S, LANDSAT and SENTINEL-2 images. Remote Sens. Environ., 114, 1747-1755, https:// doi.org/10.1016/j.rse.2010.03.002.

Hong, Y., K. Hsu, and S. Sorooshian, 2003: Precipitation estimation from remotely sensed information using ANN-cloud classification system. Eos, Trans. Amer. Geophys. Union, 84 (Fall Meet. Suppl.), Abstract H11F-0903.

-, K.-L. Hsu, S. Sorooshian, and X. Gao, 2004: Precipitation estimation from remotely sensed imagery using an artificial neural network cloud classification system. J. Appl. Meteor., 43, 1834-1853, https://doi.org/10.1175/JAM2173.1.

—, Y.-M. Chiang, Y. Liu, K.-L. Hsu, and S. Sorooshian, 2006: Satellite-based precipitation estimation using watershed segmentation and growing hierarchical self-organizing map. Int. J. Remote Sens., 27, 5165-5184, https://doi.org/10.1080/ 01431160600763428.

Hsu, K.-L., A. Behrangi, B. Imam, and S. Sorooshian, 2010: Extreme precipitation estimation using satellite-based PERSIANN-CCS algorithm. Satellite Rainfall Applications for Surface Hydrology, M. Gebremichael and F. Hossain, Eds., Springer, 49-67.

Huffman, G. J., and Coauthors, 2007: The TRMM Multisatellite Precipitation Analysis (TMPA): Quasi-global, multiyear, combined-sensor precipitation estimates at fine scales. J. Hydrometeor., 8, 38-55, https://doi.org/10.1175/JHM560.1. , D. T. Bolvin, D. Braithwaite, K. Hsu, R. Joyce, C. Kidd, E. J. Nelkin, and P. Xie, 2015: NASA Global Precipitation Measurement Integrated Multi-satellitE Retrievals for GPM (IMERG). Algorithm Theoretical Basis Doc., version 4.5, 30 pp., http://pmm.nasa.gov/sites/default/files/document_files/ IMERG_ATBD_V4.5.pdf.

Jang, J.-d., A. A. Viau, F. Anctil, and E. Bartholomé, 2006: Neural network application for cloud detection in spot vegetation images. Int. J. Remote Sens., 27, 719-736, https://doi.org/ 10.1080/01431160500106892.

Jedlovec, G. J., S. L. Haines, and F. J. LaFontaine, 2008: Spatial and temporal varying thresholds for cloud detection in goes imagery. IEEE Trans. Geosci. Remote Sens., 46, 1705-1717, https://doi.org/10.1109/TGRS.2008.916208.

Joyce, R. J., J. E. Janowiak, P. A. Arkin, and P. Xie, 2004: CMORPH: A method that produces global precipitation estimates from passive microwave and infrared data at high spatial and temporal resolution. J. Hydrometeor., 5, 487-503, https:// doi.org/10.1175/1525-7541(2004)005<0487:CAMTPG>2.0.CO;2.

Kärner, O., 2000: A multi-dimensional histogram technique for cloud classification. Int. J. Remote Sens., 21, 2463-2478, https:// doi.org/10.1080/01431160050030565.

Kidd, C., D. R. Kniveton, M. C. Todd, and T. J. Bellerby, 2003 Satellite rainfall estimation using combined passive microwave and infrared algorithms. J. Hydrometeor., 4, 1088-1104, https://doi.org/10.1175/1525-7541(2003)004<1088:SREUCP> 2.0.CO;2.

Kriebel, K., G. Gesell, M. Kästner, and H. Mannstein, 2003: The cloud analysis tool APOLLO: Improvements and validations. Int. J. Remote Sens., 24, 2389-2408, https://doi.org/10.1080/ 01431160210163065.

Lakshmanan, V., K. Hondl, and R. Rabin, 2009: An efficient, general-purpose technique for identifying storm cells in geospatial images. J. Atmos. Oceanic Technol., 26, 523-537, https://doi.org/10.1175/2008JTECHA1153.1.

Levizzani, V., J. Schmetz, H. Lutz, J. Kerkmann, P. Alberoni, and M. Cervino, 2001: Precipitation estimations from geostationary orbit and prospects for METEOSAT Second Generation. $M e$ teor. Appl., 8, 23-41, https://doi.org/10.1017/S1350482701001037.

Li, H., L. Zhang, H. Shen, and P. Li, 2012: A variational gradientbased fusion method for visible and SWIR imagery. Photogramm. Eng. Remote Sensing, 78, 947-958, https://doi.org/ 10.14358/PERS.78.9.947.

Mahrooghy, M., V. G. Anantharaj, N. H. Younan, J. Aanstoos, and K.-L. Hsu, 2012: On an enhanced PERSIANN-CCS algorithm for precipitation estimation. J. Atmos. Oceanic Technol., 29, 922-932, https://doi.org/10.1175/JTECH-D-11-00146.1.

Molnar, G., and J. Coakley Jr., 1985: Retrieval of cloud cover from satellite imagery data: A statistical approach. J. Geophys. Res., 90, 12 960-12 970, https://doi.org/10.1029/JD090iD07p12960.

Murino, L., U. Amato, M. F. Carfora, A. Antoniadis, B. Huang, W. P. Menzel, and C. Serio, 2014: Cloud detection of MODIS multispectral images. J. Atmos. Oceanic Technol., 31, 347-365, https://doi.org/10.1175/JTECH-D-13-00088.1.

Nasrollahi, N., K. Hsu, and S. Sorooshian, 2013: An artificial neural network model to reduce false alarms in satellite precipitation products using MODIS and CloudSat observations. J. Hydrometeor., 14, 1872-1883, https://doi.org/ 10.1175/JHM-D-12-0172.1.

Nguyen, P., and Coauthors, 2019: The CHRS data portal, an easily accessible public repository for PERSIANN global satellite 
precipitation data. Sci. Data, 6, 180296, https://doi.org/10.1038/ sdata.2018.296.

Otkin, J. A., and T. J. Greenwald, 2008: Comparison of WRF model-simulated and MODIS-derived cloud data. Mon. Wea. Rev., 136, 1957-1970, https://doi.org/10.1175/2007MWR2293.1.

Otsu, N., 1979: A threshold selection method from gray-level histograms. IEEE Trans. Syst. Man Cybern., 9, 62-66, https:// doi.org/10.1109/TSMC.1979.4310076.

Pahsa, A., 2006: Morphological image processing with fuzzy logic J. Aeronaut. Space Technol., 2 (3), 27-34.

Parvati, K., P. Rao, and M. Mariya Das, 2008: Image segmentation using gray-scale morphology and marker-controlled watershed transformation. Discrete Dyn. Nat. Soc., 2008, 384346, https://doi.org/10.1155/2008/384346.

Rossow, W. B., and L. C. Garder, 1993: Cloud detection using satellite measurements of infrared and visible radiances for ISCCP. J. Climate, 6, 2341-2369, https://doi.org/10.1175/ 1520-0442(1993)006<2341:CDUSMO > 2.0.CO;2.

Schmit, T. J., M. M. Gunshor, W. P. Menzel, J. J. Gurka, J. Li, and A. S. Bachmeier, 2005: Introducing the next-generation advanced baseline imager on GOES-R. Bull. Amer. Meteor. Soc., 86, 1079-1096, https://doi.org/10.1175/BAMS-86-8-1079.

Sedano, F., P. Kempeneers, P. Strobl, J. Kucera, P. Vogt, L. Seebach, and J. San-Miguel-Ayanz, 2011: A cloud mask methodology for high resolution remote sensing data combining information from high and medium resolution optical sensors. ISPRS J. Photogramm. Remote Sens., 66, 588-596, https://doi.org/10.1016/j.isprsjprs.2011.03.005.

Skamarock, W., and Coauthors, 2008: A description of the Advanced Research WRF version 3. NCAR Tech. Note NCAR/ TN-475+STR, 113 pp., https://doi.org/10.5065/D68S4MVH.

Soille, P., 2003: On the morphological processing of objects with varying local contrast. International Conference on Discrete Geometry for Computer Imagery, Springer, 52-61.

- , and M. Pesaresi, 2002: Advances in mathematical morphology applied to geoscience and remote sensing. IEEE Trans. Geosci. Remote Sens., 40, 2042-2055, https://doi.org/10.1109/ TGRS.2002.804618.

Sorooshian, S., K.-L. Hsu, X. Gao, H. V. Gupta, B. Imam, and D. Braithwaite, 2000: Evaluation of PERSIANN system satellite-based estimates of tropical rainfall. Bull. Amer. Meteor. Soc., 81, 2035-2046, https://doi.org/10.1175/15200477(2000)081<2035:EOPSSE > 2.3.CO;2.

Stowe, L. L., P. A. Davis, and E. P. McClain, 1999: Scientific basis and initial evaluation of the CLAVR-1 global clear/cloud classification algorithm for the advanced very high resolution radiometer. J. Atmos. Oceanic Technol., 16, 656-681, https:// doi.org/10.1175/1520-0426(1999)016<0656:SBAIEO > 2.0.CO;2.

Sun, L., and Coauthors, 2016: A Universal Dynamic Threshold Cloud Detection Algorithm (UDTCDA) supported by a prior surface reflectance database. J. Geophys. Res. Atmos., 121, 7172-7196, https://doi.org/10.1002/2015JD024722.

Tao, Y., X. Gao, K. Hsu, S. Sorooshian, and A. Ihler, 2016: A deep neural network modeling framework to reduce bias in satellite precipitation products. J. Hydrometeor., 17, 931-945, https:// doi.org/10.1175/JHM-D-15-0075.1.

Tian, B., M. A. Shaikh, M. R. Azimi-Sadjadi, T. H. V. Haar, and D. L. Reinke, 1999: A study of cloud classification with neural networks using spectral and textural features. IEEE Trans. Neural Networks, 10, 138-151, https://doi.org/10.1109/72.737500.

Vincent, L., and P. Soille, 1991: Watersheds in digital spaces: An efficient algorithm based on immersion simulations. IEEE Trans. Pattern Anal. Mach. Intell., 13, 583-598, https://doi.org/ 10.1109/34.87344.

Wang, D., 1997: A multiscale gradient algorithm for image segmentation using watershelds. Pattern Recognit., 30, 2043-2052, https://doi.org/10.1016/S0031-3203(97)00015-0.

Xu, K.-M., T. Wong, B. A. Wielicki, L. Parker, and Z. A. Eitzen, 2005: Statistical analyses of satellite cloud object data from CERES. Part I: Methodology and preliminary results of the 1998 El Niño/2000 La Niña. J. Climate, 18, 2497-2514, https:// doi.org/10.1175/JCLI3418.1.

Yhann, S. R., and J. J. Simpson, 1995: Application of neural networks to AVHRR cloud segmentation. IEEE Trans. Geosci. Remote Sens., 33, 590-604, https://doi.org/10.1109/36.387575.

Zahraei, A., K.-1. Hsu, S. Sorooshian, J. J. Gourley, Y. Hong, and A. Behrangi, 2013: Short-term quantitative precipitation forecasting using an object-based approach. J. Hydrol., 483, 1-15, https://doi.org/10.1016/j.jhydrol.2012.09.052.

Zhang, F., Y. Weng, J. A. Sippel, Z. Meng, and C. H. Bishop, 2009: Cloud-resolving hurricane initialization and prediction through assimilation of Doppler radar observations with an ensemble Kalman filter. Mon. Wea. Rev., 137, 2105-2125, https://doi.org/ 10.1175/2009MWR2645.1.

, — - J. F. Gamache, and F. D. Marks, 2011: Performance of convection-permitting hurricane initialization and prediction during 2008-2010 with ensemble data assimilation of innercore airborne Doppler radar observations. Geophys. Res. Lett., 38, L15810, https://doi.org/10.1029/2011GL048469.

—, M. Minamide, R. G. Nystrom, X. Chen, S.-J. Lin, and L. M. Harris, 2019: Improving Harvey forecasts with next-generation weather satellites. Bull. Amer. Meteor. Soc., https://doi.org/ 10.1175/BAMS-D-18-0149.1, in press.

Zhang, X., F. Jia, S. Luo, G. Liu, and Q. Hu, 2014: A marker-based watershed method for X-ray image segmentation. Comput. Methods Programs Biomed., 113, 894-903, https://doi.org/ 10.1016/j.cmpb.2013.12.025.

Zhang, Y., and B. Guindon, 2003: Quantitative assessment of a haze suppression methodology for satellite imagery: Effect on land cover classification performance. IEEE Trans. Geosci. Remote Sens., 41, 1082-1089, https://doi.org/10.1109/ TGRS.2003.811817.

— — - and J. Cihlar, 2002: An image transform to characterize and compensate for spatial variations in thin cloud contamination of Landsat images. Remote Sens. Environ., 82, 173-187, https://doi.org/10.1016/S0034-4257(02)00034-2.

Zhang, Y., F. Zhang, and D. J. Stensrud, 2018: Assimilating all-sky infrared radiances from GOES-16 ABI using an ensemble Kalman filter for convection-allowing severe thunderstorms prediction. Mon. Wea. Rev., 146, 3363-3381, https://doi.org/ 10.1175/MWR-D-18-0062.1.

Zhu, Z., S. Wang, and C. E. Woodcock, 2015: Improvement and expansion of the Fmask algorithm: Cloud, cloud shadow, and snow detection for Landsats 4-7, 8, and Sentinel 2 images. Remote Sens. Environ., 159, 269-277, https://doi.org/10.1016/ j.rse.2014.12.014. 